\title{
Low Back Pain and Associated Factors among Civil Service Sectors Office Workers in Southern Ethiopia
}

\author{
Fanta $\mathbf{M}^{1}$, Alagaw $\mathbf{A}^{1}$, Kejela $\mathbf{G}^{1}$, Tunje $\mathbf{A}^{1}$ \\ 'Department of Public Health, College of Medicine and Health Science, Arba Minch University, Arba Minch, \\ Ethiopia
}

\section{ABSTRACT}

Introduction: Low back pain is one of the most common work-related health problems among office workers. Low back pain has been identified as one of the most costly disorders among the worldwide working population. However, there is a lack of information on associated factors with low back pain.

Objectives: This study was aimed to assess the prevalence and factors associated with low back pain among civil service sectors office workers in Southern Ethiopia.

Methods: Institution based cross-sectional study was conducted among 625 civil service sectors office workers, who work in the sitting position, in Sodo town, Southern Ethiopia from March 10 to June 20, 2017. The sampling frame was obtained from civil service office and simple random sampling technique was used. Data was collected by using a pretested structured questionnaire adapted from Standardized Nordic musculoskeletal Questionnaires and modified Oswestry through face to face interview and by using a checklist for observations, which was measured by diploma nurses. Binary logistic regression was conducted and variables with $p<=0.20$ in bivariate analysis were fitted into the multiple logistic regression models to identify factors associated with low back pain. Variables with $\mathrm{P}$ value $<0.05$ were considered as statistically significant predictors of low back pain.

Results: Out of the 630 sample size, 625 participants responded making a response rate of $99 \%$. The 12 -month prevalence of low back pain among civil service sectors office workers in this study was $38.4 \%$ (95\% Cl:0.34, 0.42 ). This study found that, being obese (AOR $[95 \% \mathrm{Cl}]=6.3[4.29-9.09])$, having smoking history (AOR $[95 \% \mathrm{Cl}]=5.2[2.57-10.82])$, poor sitting posture $(\mathrm{AOR}[95 \% \mathrm{Cl}]=2.6[1.61-4.30])$, having job stress $(\mathrm{AOR}[95 \% \mathrm{Cl}]$ $=5.9[3.44-10.25]$ ), having no rest break during workday (AOR $[95 \% \mathrm{Cl}]=3.2[1.82-5.62]$ ), sitting $>6$ hours per day (AOR $[95 \% \mathrm{Cl}]=16.08[14.4-19.3])$ and using computer frequently (AOR $[95 \% \mathrm{Cl}]=4.3[2.09-5.47])$ are significantly associated with low back pain.

Conclusion: The 12-month prevalence of low back pain in this study is high (38.4\%). Therefore, healthy lifestyle habits, good awareness of sitting posture and better ergonomic facilities and psychosocial support to workers were recommended to decrease the effects of predisposing factors of low back pain.

Key words: Associated factors, Low back pain, Prevalence, Office workers, Sodo town

DOI: https://doi.org/10.3126/ijosh.v10i1.29883

\section{Introduction}

ow back pain is a common health problem among the

- general population and a major cause of disability

Date of submission: 22.07.2019

Date of acceptance: 27.06 .2020

\section{Corresponding Author}

Mulatu Fanta

Department of Public Health

College of Medicine and Health Science

Arba Minch University, Arba Minch, Ethiopia

Email: fantamulat@gmail.com that affects work performances and well-being. ${ }^{1}$ Low back pain (LBP) has been identified as one of the most costly disorders among the working population worldwide. ${ }^{2}$ Current estimates suggest that 632.045

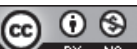

This journal is licensed under a Creative Commons AttributionNon Commercial 4.0 International License. 
million people worldwide suffer from low back pain. Low back pain was among top 10 diseases and the sixth most important contributor to the global disease burden (death and disability) and has a greater impact on global health than malaria, Human Immunodeficiency Virus (HIV), preterm birth complications, obstructive pulmonary diseases, tuberculosis, and diabetes or lung cancer. ${ }^{1,3}$ Prevalence of LBP varied depending on definitions and study populations and also differs from countries to countries. ${ }^{3}$

Globally, there is a lifetime incidence of $40 \%$, affecting as much as $80 \%$ of people in developed countries. ${ }^{4}$ Prevalence of LBP among African Continent is also rising and is of concern, but the lack of information on the prevalence of LBP in developing countries is a significant shortcoming. ${ }^{5}$ Study conducted in Nigeria indicates that the 12-month prevalence of low back pain in civil service in Ibadan was $38 \%{ }^{6}$

The current rapid economic development has brought changes in workplaces in developing countries, including Ethiopia. However, statistics on LBP in Ethiopia is scarce. The consequences of low back pain were far-reaching and lead to a negative economic impact, which includes an increased absence from work and lost productivity. Low back is causing global implications to various sectors such as economical, societal and public health. ${ }^{3,7,8}$

This common health complaint usually begins at age 20-40 years but is mostly noticed in individuals aged 40-80 years. The distribution among men and women is not clear. ${ }^{9-11}$ The studies undertaken in different countries indicated that the reasons for low back pain are associated with obesity, smoking, weight lifting, stooping, prolonged sitting, poor fitness level, especially among those with a sedentary lifestyle and awkward posture at work. ${ }^{12}$

The prevalence of low back pain and its consequences for sickness leave, limitations of work activity and permanent disability has been thoroughly documented in many office workers. ${ }^{13}$ The nature of office work and the office environment has been associated with increased risks of LBP. ${ }^{14}$

Low back pain results in significant levels of disability, producing significant restrictions on usual activity and participation, including the inability to work. ${ }^{8}$

The relationship between occupation and the risk of developing low back pain (LBP) is not well understood. ${ }^{15,16}$ In Ethiopia, information regarding low back pain was rare, and very limited attempts have been made to investigate the prevalence and associated factors. ${ }^{7,17}$ Many quantitative research were done in different parts of the country on LBP issues; especially on industrial, hospital staffs and office workers. But there is a lack of information on associated factors with LBP which makes people to not work properly. ${ }^{18}$

Knowing the magnitude and associated factors low back pain demonstrates that there is a significant need for preventive activities. So, this study aimed to assess the prevalence and factors associated with low back pain (LBP) among civil service sector office workers in Sodo town, Wolaita zone, Southern Ethiopia.

\section{Methods}

An institution-based cross-sectional study was conducted among 625 office workers from March 10 to June 20, 2017, in Sodo town, Southern Ethiopia.

All civil-servants who were working in the sitting position in Sodo town were the source population and all office workers who can fulfil the inclusion criteria were the study population for this study. Individuals with 20 years \& above who were involved in office sedentary work and worked at least for two years were included in the study. A worker who had had any previous illness and/or injuries that might have contributed to LBP, female workers who were pregnant, workers who had had a past medical history of LBP without occupational hazards and workers who have had past slipping/fall history were excluded from the study.

\section{Sample Size determination and sampling procedures}

The required sample size was determined by using EPI INFO version 7 , considering the following assumption. Prevalence of the outcome in exposed group $45.5 \%{ }^{19}$, the two-sided significance level of $95 \%$, power of $80 \%$ and one to one ratio of unexposed to exposed group, $10 \%$ for non- response \& design effect 1.5 for multistage sampling. The total sample size calculated was 630 . To get the calculated sample size, multistage sampling was used. First, the sampling frame was obtained from civil service office. In Sodo town, there are 40 civil service sector offices. Out of 40,8 sectors were selected by simple random sampling. Then, the number of workers from each office was identified and proportionally allocated to their size. Lastly, the participants were selected by using the lottery method. 


\section{Measurements}

Ergonomics; is the field of study that seeks to fit the job to the person, rather than the person to the job. ${ }^{20}$

Awareness of Ergonomics knows of adapted work to a specific person by designing tasks \& tools or equipment to fit the individual to prevent injuries to the musculoskeletal system.

Awareness of Ergonomics score is a composite score given for 8 items selected according to Occupational Safety and Health Agency (OSHA) guidelines. If an individual who scores above half of the questions answered as (yes), then the awareness on ergonomic scores was good. An individual who scores at least less than half of the questions answered as (no), then the awareness on ergonomic scores was poor

Pain is usually an uncomfortable sensation resulting from an activity that injures or can potentially harm the body's tissues. ${ }^{3}$

Low back pain is defined as any "non-traumatic musculoskeletal disorder causing from movement limitation to affecting the low back. ${ }^{21}$

No pain is defined as low back pain not attributed to recognizable. ${ }^{3}$

Low back pain score is a composite score given for 15 variables selected to determine the LBP. If an individual who scores above half of the questions answered as (yes), then the scores make, no pain. An individual who scores at least less than half of the questions answered as (no), then the pain scores were considered as having LBP.

Body Mass Index is the body weight in kilograms, divided by the value of body height in meters squared $(\mathrm{kg} / \mathrm{m} 2)$

Social support: is the interaction in the Work environments that facilitate mutual support between colleagues and do not tolerate antisocial behaviour. ${ }^{22}$

Social support score is the scoring for the 6 questions on Social support on five point's scale. The total possible scores varied from 6 to 30 with the neutral point at 15. A total score above neutral point indicates having social support and below, have no social support.

Job stress: refers to a physical and mental response triggered off by an employee's when his/her capabilities do not meet his organizations demands. ${ }^{23}$
Job stress score is a composite score given for 20 items selected and individuals who score equal to half of the questions as (yes) was considered as having Job stress. If individuals who score greater than half (no) was considered to have no Job stress.

Job satisfaction is a feeling of affiliation that a person derives from his job and the context in which he operates. ${ }^{24}$

Job satisfaction score is the scoring for the 10 questions on job satisfaction on four point's scale, (strongly agree, slightly agree, slightly disagrees and strongly disagree). The total possible scores varied from 10 to 40 with a neutral point at 20. A total score above neutral point indicates satisfaction and below, dissatisfaction starts.

Visual Analogue Scale (VAS) is usually a horizontal line, $100 \mathrm{~mm}$ in length, anchored by word descriptors at each end, The workers are asked to rate their pain and marks on the line the point that they feel represents their perception of their current state. ${ }^{25}$

VAS score is determined by measuring in millimeters from the left-hand end of the line to the point that the patient marks with mild (1-2), moderate (3-7) and maximum pain (8-10).

\section{Data collection procedures}

Anthropometric measurement for the height and weight of the participants were measured wearing light clothes and no shoes/ bare feet by using the Stature meter and portable weighing. Data was collected through a faceto-face interview to gather relevant information focused on: Socio-demographic factors (age, educational background, marital status and income), lifestyle (smoking, chewing chat, and drinking alcohol) and physical exercise, work-related factors such as daily sitting hours, worked a year, history of previous work and extra professional activity, means of transportation, home to work journey length and duration, LBP mode of onset, frequent use of the computer, and triggering factor by using structured questioners prepared in English and translated to local language.

Four diploma nurses collected the data and two public health officers supervised the data collection procedure.

\section{Data management and quality assurance}

The training was given for data collectors and supervisors about the objective, questionnaire, 
methodology and ethical issues of the study to have a common understanding among them.

To check the accuracy and validity of the questionnaire, pre-testing of the questionnaire was done among 32 respondents from other town sectors that were not included in the study to assure accuracy and to change any questions which were not easy to understand for respondents. English version questionnaire was translated to Amharic and then translated back to English to ensure its consistency.

\section{Data processing and analysis}

The data was checked and entered using Epi-Info version 7.2. It was cleaned and edited by simple frequencies and cross-tabulation before analysis. For analysis, the data was exported to Statistical Package for Social Sciences (SPSS) Version 20.0 and was checked for missing values before analysis. Descriptive statistics and numerical summary measures were present using frequencies distribution tables to describe the study population to relevant variables. All continuous and measured variables were categorized to ease analysis. Binary logistic regression was conducted and all variables with $p<=0.20$ in the bivariate analysis was fitted into the multiple logistic regression model to identify factors associated with the occurrence of low back pain. In multivariable logistic regression, the strength of association was expressed in odds ratio and its $95 \%$ confidence interval. Variables with $p$ values $<0.05$ were considered as of significant predictors of low back pain.

\section{Ethical consideration}

Ethical clearance was obtained from Arba Minch University Ethical Review Committee. A formal letter was also submitted to Wolaita zone civil service office and subsequently to civil service sector offices of Sodo town where the study took place. Written permission from the civil service sector office of the respondents was obtained a day before the data collection time. All participants were informed that their response kept confidential. Before conducting each structured questionnaire interviews, the aim, purpose, benefits and method of the study was clearly explained to the participant.

\section{Results}

Socio-demographic and lifestyle characteristics of the respondents

Out of the total 630 participants included in the study,
625 participants responded to the questionnaire, making a response rate of $99 \%$. The participants' ages ranged from 20-60 years, with a mean age of 39.47 years (SD =8.9). Of these participants, $217(34.7 \%)$ were female, 270 (43.2\%) were between 31 - 40 years of age and 309 (49.4\%) were protestant. Three hundred and forty (54.4\%) were married and 307 $(49.1 \%)$ were of Wolayta ethnic group. Three hundred and two $(57.4 \%)$ were educated to degree level and $504(80.6 \%)$ of the participants had a monthly income of 4501-5000 Birr. Regarding the BMI of office workers, $404(64.6 \%)$ was between $(18.5-24.9 \mathrm{~kg} / \mathrm{m} 2)$. About $344(55.0 \%)$ of respondents did not participate in any sport. The study showed that participants who do not drink alcohol, chewing chat nor smoke cigarette were reported by 400 (64\%), 433 (69.3\%) and 464 (74.2\%) of respondents respectively (Table 1 ).

\section{Prevalence and characteristics of low back pain among respondents}

Out of 625 participants, $240(38.4 \%)$ reported low back pain at least for one day in the past 12 months. Among those who experienced low back pain, 76 (12.2\%) participants have mild symptoms (1-2), 56 (9.0\%) have moderate symptoms (3-7) and 108 (17.3\%) have severe symptoms of pain (8-10). The majority of the respondents $(17 \%)$ experienced severe pain intensity from (8-10). Work absenteeism $<5$ days was reported in $127(52.9 \%)$. Regarding the nature of pain onset, in $139(57.9 \%)$ participants, the pain was developed gradually and $101(42.1 \%)$ reported sudden onset at their work activity. Most of the respondents with LBP $95(39 \%)$ indicated the immediate/current cause of low back as sitting during their work, 56 (23\%) maintain standing, 42 (18\%) maintain twisting, 35 (14\%) maintain forward bending and $12(5 \%)$ were not able to remember the cause of LBP. Regarding the occurrence of LBP, 135 (60.4\%) and 95 (39.6\%) have experienced the pain more than once and once respectively. About $223(92.9 \%)$ of respondents were often tired after work, whereas, $17(7.1 \%)$ respondents were not often tired after work.

\section{Awareness of ergonomics and psycho-social factors}

From the total respondents, $350(56.0 \%)$ have stated poor sitting posture and 275 (44.0) respondents were aware of good sitting posture. About 416(66.6\%) respondents were satisfied by their job. Four hundred and sixty-five $(74.4 \%)$ respondents were engaged in a stressful job. Most of the respondents $435(69.6 \%)$ and 
190 (30.4) were engaged in having \& not having social support respectively.

\section{Job characteristics of the respondents}

Majority of office workers, 208 (33.3\%) had more than 6-10 years of working experience. Most of the respondents were working eight hours a day and 447 $(71.5 \%)$ of them did not use fixed rest break in their work time whereas 178 (28.5\%) have used fixed rest break. Most of the respondents 213 (34.1\%) were sitting for more than 4-5 hrs per day. Five hundred and eightyfour $(93.4 \%)$ respondents were working $\geq 5$ days per week. Two hundred and fifty-eight $(41.3 \%)$ respondents were currently working with sitting-forward bending. Three hundred and eighty-nine $(62.2 \%)$ respondents participated in extra work activities after office work. Also, most of the respondents 512 (88.9\%) have participated in the frequent use of a computer. Office workers who had a history of another profession that involves before becoming office workers were sitting $204(32.6 \%)$, standing 227(36.3\%), un-comfortable posture $188(30.1 \%)$ and moving loads $6(1.0 \%)$ (Table 2).

\section{Factor Associated with Low Back Pain}

\section{Binary logistic regression analysis}

In the bivariate analysis, age, obesity, smoking, poor sitting posture, job stress, absence of rest break, sitting hours per days, frequent use of computer and job satisfaction shows statistically significant association with low back pain (Table 3).

\section{Multivariable logistic regression analysis}

The backward logistic regression was carried out to determine the overall effects of explanatory variables on the dependent variables. Among the explanatory variables, seven variables were statistically significant and remained in the last step in the model. These were
BMI/obesity, smoking cigarette, poor sitting posture, job stress, absence of rest break, sitting hours per day and frequent computer use.

The result obtained from multivariable logistic regression showed that Body Mass Index (BMI/ obesity) is significantly associated with low back pain. Office worker those who had high BMI/obesity were 6.32 times more likely to have low back pain compared to those who had normal weight $(\mathrm{AOR}[95 \% \mathrm{Cl}]=6.32$ [4.29 - 9.09]) and office worker those who had smoking history were 5.27 times more likely to have low back pain compared to those who never smoked (AOR $[95 \% \mathrm{Cl}]=5.27[2.57-10.82])$.

Similarly, office workers with poor awareness on sitting posture were 2.63 times more likely to have low back pain compared to workers who had good awareness on sitting posture $(\mathrm{AOR}[95 \% \mathrm{Cl}]=2.63[1.61-4.30])$.

On the other hand, workers with job stress were 5.9 times more likely to experience/ have LBP compared to those who did not report job stress in the workplace $(\mathrm{AOR}[95 \% \mathrm{Cl}]=5.93[3.44-10.25])$.

Office workers those who did not take rest break during workday were 3.2 times more likely to develop low back pain compared to the office worker who had rest break during the workday $(\mathrm{AOR}[95 \% \mathrm{Cl}]=3.20[1.82-$ 5.62]) and office workers with $>6$ hours sitting per day were 16 times more likely to develop LBP compared to office workers with less than two hours sitting per day $(\mathrm{AOR}[95 \% \mathrm{Cl}]=16.0[14.4-19.3])$

Office workers those who frequently use a computer were 4.3 times more likely to develop low back pain compared to the office worker who didn't participate in the frequent use of a computer during their work time $($ AOR $[95 \% \mathrm{Cl}]=4.3[2.09-5.47])$ (Table 4). 
Table 1: Socio-demographic and life style characteristics of respondents in Sodo town, March, 2017 ( $n=625)$

\begin{tabular}{|c|c|c|c|}
\hline Variables & Categories & Frequency (n) & Percent (\%) \\
\hline \multirow{4}{*}{ Age } & $20-30$ & 80 & 12.8 \\
\hline & $31-40$ & 270 & 43.2 \\
\hline & $41-50$ & 102 & 16.3 \\
\hline & $51-60$ & 173 & 27.7 \\
\hline \multirow{3}{*}{ Marital status } & Single & 260 & 41.6 \\
\hline & Married & 340 & 54.4 \\
\hline & Divorced & 25 & 4.0 \\
\hline \multirow{4}{*}{ Levels of education } & Certificate & 28 & 4.5 \\
\hline & Diploma & 256 & 32.0 \\
\hline & Degree & 302 & 57.4 \\
\hline & Masters & 39 & 4.0 \\
\hline \multirow{4}{*}{ Ethnicity } & Wolayta & 307 & 49.1 \\
\hline & Gurage & 43 & 6.9 \\
\hline & Amara & 272 & 43.5 \\
\hline & Others & 3 & 0.5 \\
\hline \multirow{4}{*}{ Religious } & Orthodox & 309 & 49.4 \\
\hline & Muslim & 207 & 33.1 \\
\hline & Protestant & 107 & 17.1 \\
\hline & Others & 2 & 3 \\
\hline \multirow{3}{*}{ Income per month(birr) } & $<3501$ & 43 & 6.8 \\
\hline & $3501-4500$ & 76 & 12.6 \\
\hline & $4501-5000$ & 504 & 80.6 \\
\hline \multirow{3}{*}{ BMI } & $18.5-24.9$ & 404 & 64.6 \\
\hline & $25-29.5$ & 75 & 12 \\
\hline & $>30$ & 146 & 23.4 \\
\hline \multirow{3}{*}{ Drinking alcohol } & Former drinker & 137 & 21.9 \\
\hline & Current drinker & 88 & 14.1 \\
\hline & Never drinker & 400 & 64.0 \\
\hline \multirow{3}{*}{ Chat chewing } & Former chewer & 153 & 24.5 \\
\hline & Current chewer & 39 & 6.2 \\
\hline & Never chewer & 433 & 69.3 \\
\hline \multirow{3}{*}{ Smoking } & Former smoker & 144 & 23.1 \\
\hline & Current smoker & 14 & 2.7 \\
\hline & Never smoker & 464 & 74.2 \\
\hline
\end{tabular}

*=Other ethnic groups Derash, koyra, Dawuro

Table 2: Job/work characteristics of the respondents in civil service sector office workers in Sodo town, March, $2017(n=625)$

\begin{tabular}{llcc}
\hline Variables & Categories & Frequency(n) & Percent (\%) \\
\hline \multirow{3}{*}{ Sitting hours per day } & $<2 \mathrm{hrs}$ & 107 & 17.1 \\
& $2-3 \mathrm{hrs}$ & 147 & 23.5 \\
& $4-5 \mathrm{hrs}$ & 213 & 34.1 \\
& $6 \mathrm{hrs}$ \& above & 158 & 25.3 \\
& $2-5 y r s$ & 172 & 27.5 \\
Working years & $6-10 \mathrm{yrs}$ & 208 & 33.3 \\
& $11-15 y r s$ & 188 & 30.1 \\
& $16-20 y r s$ & 52 & 8.3
\end{tabular}




\begin{tabular}{llcc}
\multirow{2}{*}{ Frequently use the computer } & Yes & 512 & 88.9 \\
& No & 113 & 18.1 \\
\cline { 2 - 3 } Currently work activities are mostly & sitting-forward bending & 258 & 41.3 \\
& sitting-twisting & 98 & 15.7 \\
& sitting-bending-lifting & 140 & 22.4 \\
& Sitting normal-prolonged & 129 & 20.6 \\
\hline \multirow{2}{*}{ Other work in the past } & Sitting for long period & 204 & 32.6 \\
& Standing for long period & 227 & 36.3 \\
\multirow{2}{*}{ Extra Professional activity } & With un-comfortable posture & 188 & 30.1 \\
& With moving loads & 6 & 1.0 \\
\hline
\end{tabular}

Table 3: Binary logistic regression analysis showing factors associated with low back pain among civil service sector office workers in Sodo town, March, $2017(n=625)$.

\begin{tabular}{|c|c|c|c|c|}
\hline \multirow{2}{*}{ Variable } & \multicolumn{2}{|c|}{ Present of low back pain } & \multirow{2}{*}{ COR (95\% Cl) } & \multirow{2}{*}{$p$-value } \\
\hline & Yes (\%) & No $(\%)$ & & \\
\hline \multicolumn{5}{|l|}{ Age } \\
\hline $20-30$ & $4(5.0)$ & $76(94.9)$ & 1 & \\
\hline $31-40$ & $71(26.3)$ & 199(73.7) & $6.7(2.39,9.20)^{\star}$ & 0.021 \\
\hline $41-50$ & $53(52.0)$ & $49(48.0)$ & $12.5(6.99,13.38)^{*}$ & 0.037 \\
\hline $51-60$ & $112(64.7)$ & $61(35.3)$ & $14.8(2.17,17.96)^{*}$ & 0.001 \\
\hline \multicolumn{5}{|l|}{ BMI } \\
\hline $18.5-24.9$ & $75(18.6)$ & $329(81.4)$ & 1 & \\
\hline $25-29.5$ & $40(53.3)$ & $35(46.7)$ & $5.0(2.98,8.41)^{*}$ & 0.004 \\
\hline$>30$ & $125(85.6)$ & $21(14.4)$ & $6.1(6.43,8.17)^{*}$ & 0.001 \\
\hline \multicolumn{5}{|l|}{ Smoking } \\
\hline Former smoker & $63(75.9)$ & $20(24.1)$ & $6.44(3.77,11.01)^{\star}$ & 0.001 \\
\hline Current smoker & $8(29.6)$ & $19(70.4)$ & $0.84(0.37,0.86)^{*}$ & 0.001 \\
\hline Never smoker & $169(32.8)$ & $346(78.7)$ & 1 & \\
\hline \multicolumn{5}{|c|}{ Awareness on sitting } \\
\hline Good & $64(23.3)$ & 211(76.7) & 1 & \\
\hline Poor & $176(53.3)$ & $\begin{array}{c}174(49.7) 3.33 \\
(2.35,4.73) 0.020\end{array}$ & $3.33(0.35,2.73)$ & 0.122 \\
\hline \multicolumn{5}{|l|}{ Job Stressful } \\
\hline & & $58(36.2)$ & & \\
\hline Yes & $102(63.8)$ & $\begin{array}{c}4.16(2.85,6.08) \\
0.0001\end{array}$ & $4.16(2.85,6.08)$ & 0.001 \\
\hline No & $138(29.7)$ & $327(70.3)$ & 1 & \\
\hline \multicolumn{5}{|c|}{ Present of rest break } \\
\hline Yes & $46(25.8)$ & $132(74.2)$ & 1 & \\
\hline No & $194(43.4)$ & $253(56.6$ & $2.2(1.49,3.23)^{\star}$ & 0.011 \\
\hline \multicolumn{5}{|c|}{ Sitting hours per days } \\
\hline$<2 \mathrm{hrs}$ & $5(8.1)$ & $57(91.9)$ & 1 & \\
\hline 2-3hrs & $6(11.3)$ & $47(88.7)$ & $1.45(1.41,5.07)^{*}$ & 0.024 \\
\hline 4-5hrs & $42(35.3)$ & $77(64.7)$ & $6.21(2.31,6.43)^{\star}$ & 0.009 \\
\hline $6>\mathrm{hrs}$ & $187(47.8)$ & $204(52.2)$ & $10.4(4.10,11.63)^{*}$ & 0.001 \\
\hline \multicolumn{5}{|c|}{ Frequently computer user } \\
\hline Yes & $229(41.3$ & $325(58.7)$ & $3.84(1.97-7.47)^{*}$ & 0.001 \\
\hline No & $11(15.5)$ & $60(84.5)$ & 1 & \\
\hline Job satisfaction & & & & \\
\hline
\end{tabular}


Fanta M et al.

Table 4: Logistic regression analysis showing factors associated with low back pain among civil service sector office workers in Sodo town, South Ethiopia, 2017.

\begin{tabular}{|c|c|c|c|c|}
\hline \multirow{2}{*}{ Variable } & \multicolumn{2}{|c|}{ Presence of LBP } & \multirow{2}{*}{ COR(95\%Cl) } & \multirow{2}{*}{ AOR $(95 \% \mathrm{Cl})$} \\
\hline & Yes (\%) & No (\%) & & \\
\hline \multicolumn{5}{|l|}{ BMI } \\
\hline $18.5-24.9$ & $75(18.6)$ & $329(81.4)$ & 1 & 1 \\
\hline $25-29.5$ & $40(53.3)$ & $35(46.7)$ & $5.01(2.98,8.41)^{*}$ & $5.9(3.07-11.43)^{\star *}$ \\
\hline$>30$ & $125(85.6)$ & $21(14.4)$ & $6.11(1.43,7.17)^{*}$ & $6.3(4.29-9.09)^{\star *}$ \\
\hline \multicolumn{5}{|l|}{ Smoking } \\
\hline Former smoker & $63(75.9)$ & $20(24.1)$ & $6.4(3.77,11.01)^{*}$ & $5.2(2.57-10.82)^{* *}$ \\
\hline Current smoker & $8(29.6)$ & $19(70.4)$ & $0.84(0.37,0.86)^{*}$ & $0.56(0.63-0.78)^{* *}$ \\
\hline Never smoker & 169(32.8) & $346(78.7)$ & 1 & 1 \\
\hline \multicolumn{5}{|c|}{ Awareness on sitting } \\
\hline Good & $64(23.3)$ & $211(76.7$ & 1 & 1 \\
\hline Poor & $176(53.3)$ & $174(49.7)$ & $3.3(0.057,0.01)^{*}$ & $2.6(1.61-4.30)^{* *}$ \\
\hline \multicolumn{5}{|l|}{ Job Stressful } \\
\hline Yes & $102(63.8)$ & $58(36.2)$ & $4.1(2.85,6.08)$ & $5.9(3.44-10.25)^{* *}$ \\
\hline No & $138(29.7)$ & $327(70.3)$ & 1 & 1 \\
\hline \multicolumn{5}{|c|}{ Present of rest break } \\
\hline Yes & $46(25.8)$ & 132(74.2) & 1 & 1 \\
\hline No & $194(43.4)$ & $253(56.6)$ & $2.2(1.49,3.23)^{*}$ & $3.20(1.82-5.62)^{\star *}$ \\
\hline \multicolumn{5}{|c|}{ Sitting hours / days } \\
\hline$<2 \mathrm{hrs}$ & $5(8.1)$ & $57(91.9)$ & 1 & 1 \\
\hline 2-3hrs & $6(11.3)$ & $47(88.7)$ & $1.45(1.41,5.07)^{*}$ & $2.2(0.46-1.96)$ \\
\hline $4-5 \mathrm{hrs}$ & $42(35.3)$ & $77(64.7)$ & $6.21(2.31,6.43)^{*}$ & $10.2(8.8-13.40)^{\star *}$ \\
\hline $6>\mathrm{hrs}$ & $187(47.8)$ & $204(52.2)$ & $10.4(4.10,11.63)^{*}$ & 16.0(14.4-19.3) \\
\hline \multicolumn{5}{|c|}{ Frequent use of computer } \\
\hline Yes & $229(41.3)$ & $325(58.7)$ & $3.84(1.97,7.47)^{*}$ & $4.3(2.09-5.47)^{\star *}$ \\
\hline No & $11(15.5$ & $60(84.5)$ & 1 & 1 \\
\hline
\end{tabular}

Keys: $\mathbf{C l}=$ confidence interval, $\mathbf{A O R}=$ adjusted odds ratio, ${ }^{*}$ Candidate variables for multivariable analysis at $p$-value $\leq 0.2$. **statistically significant at $p<0.05$ in multivariable logistic regression; $1=$ used as reference category

\section{Discussion}

This study found that the twelve-month prevalence of LBP among civil service sectors office workers in Sodo town is $38.4 \%$ [ $95 \% \mathrm{Cl}=(0.34,0.42)]$. The result of this study is similar to the result in the world in which, $37 \%$ of LBP is attributed to occupation. ${ }^{2}$ This finding is similar with a study conducted among 840 office workers in civil service in Ibadan, Nigeria, in which the 12-month prevalence of low back pain was $38 \%{ }^{6}$ Similarly, the finding was also consistent with another study conducted among 648 Greek public office workers in which $37.8 \%$ of office workers presented with the one-year prevalence of LBP. ${ }^{26}$ However, the finding of this study is lower than a study conducted in Germany, in which one-year prevalence of $60 \%$ of low back pain ${ }^{2}$ and study conducted in South Brazil which presented a one-year prevalence of low back pain $50.2 \% .{ }^{27}$ The finding of this study is higher than studies conducted in South Africa (37\%) and Nigeria $(26 \%) .^{5,15}$ These variations may be due to the socioeconomic gap, the measurement tools, sample size, and study population.

Many factors are associated with low back pain in this study. BMI/Obesity, smoking, sitting posture, job stress, absence/presence of rest break, sitting hours per day and frequent use of computer were significantly associated with Low Back Pain.

Obesity is significantly associated with low back pain, office workers who are obese were 6.32 times more likely to have low back pain compared to those workers with normal weight. This finding is consistent with the study conducted in Brazil, which revealed that workers who are obese were 2.3 times more likely to have low back pain compared to those workers with 
normal weight. ${ }^{28}$ This finding is also consistent with the study conducted in Lebanon that revealed workers who are obese were 1.1 times more likely to have low back pain compared to those with normal weight. ${ }^{29}$ And meta-analysis including 33 studies showed that, obese individuals were 1.3 times more likely to have low back pain compared to those with normal weight. ${ }^{3}$ Similarly, in this study, overweight is significantly associated with low back pain. Office workers who are overweight were 5.9 times more likely to have low back pain compared to those with normal weight. This finding is also consistent with the study conducted in Brazilian that revealed, workers who are overweight were 1.4 times more likely to have low back pain compared to those workers with normal weight. ${ }^{28}$ This association may be as a result of increased physical loading in the middle parts of the body, as well as modifications in the gravitational axis due to increased body mass.

Smoking is another factor that is associated with low back pain in this study. This study revealed that office workers who had former smoking history were 5.27 times more likely to have low back pain compared to those who are never smokers. This finding is inconsistent with a study conducted in Kurdistan Region, Iraq, which revealed that workers who are current smokers were 10.8 times more likely to have low back pain compared to those who are former smokers. ${ }^{30}$ The possible explanation of this inconsistency could be the difference in reference category, in this study; never smokers were used as a reference because this group was less risk to LBP than those who had a former smoking history. But the study in Iraq used former smokers as the reference category. A possible explanation for the association might be due to smoking causing calcium deficiency by reducing the absorption of the quantity of calcium from the diet, which the body needs for building strong bones.

This study showed that workers who had no rest break during their workday were 3.2 times more likely to have LBP compared to those who had rest break during the workday. This study finding is similar to study conducted in Kigali, Rwanda, in which, respondents having no break off during working time were 3.9 times more likely to have low back pain compared to those who had time to rest during the workday. ${ }^{31}$ This may be due to lack of time to rest which exaggerates the risk of getting low back pain.

Working in a stress condition was found to be associated with low back pain. Office workers with job stress were 5.9 times more likely to have LBP compared to those who have not reported job stress. This finding is supported by other researches undertaken in the same title in Thailand that shows, respondents who were mentally stressed at their working environment were 3.1 times more likely to have LBP compared to those who have not reported job stress. ${ }^{14}$ This might be due to the lack of capabilities in handling stress among office workers.

This study showed that respondents who had poor sitting posture were 2.6 times more likely to have LBP compared to workers who had good sitting posture. This finding is consistent with the study conducted in Lebanon. ${ }^{32}$ The finding is also similar to a study conducted in Thailand that revealed, workers who had poor sitting posture were 3.8 times more likely to have low back pain compared to those who had good sitting posture. ${ }^{14}$ This might be due to the lack of capabilities in handling office ergonomics.

In this study, sitting time per day is significantly associated with low back pain. Office workers who sit more than 4 hours per day were 10.2 times more likely to have low back pain compared to those who sit for less than two hours per day. Similarly, workers those who sit for more than 6 hours per day were 16 times more likely to have low back pain compared to those who sit for less than two hours per day. The findings is consistent with study conducted in Ibadan, Nigeria ${ }^{6}$, Greece as well as Malaysia. ${ }^{33}$ The reason might be due to the static posture that increases stress in the back, prolonged static posture without rest leads to awkward postures that contribute to back problems and muscle strains.

In the present study, frequent computer use' is significantly associated with low back pain. Office workers who frequently use a computer were 4.3 times more likely to have low back pain compared to those who did not use the computer frequently during their working time. This finding is similar to findings from studies conducted in Kigali, Rwanda and Iran which shows respondents who frequently use a computer were 3.5 and 3.2 times more likely to have low back pain as compared to those who didn't use a computer during their working time respectively. ${ }^{21,31}$ The possible explanation for this finding might be due to the presence of a computer in the workplace leads to a set of peculiar characteristics of the workstation which require the workers to stay in a static posture for long periods. 
Use of visual analogues scale (VAS) which is a worldwide accepted, standardized and well valid instrument to measure pain intensity level can be considered as the strength of this study. However, the nature of the study design might affect the clear causal relationship between exposures and outcome variable which is the limitation of the study.

\section{Conclusions and Recommendations}

The prevalence of LBP among civil service sectors office workers in this study was $38.4 \%$. The study found the preventable predisposing factors such as BMI/Obesity, smoking, poor sitting posture, job stress, absence of rest break, sitting hours per day and frequent use of a computer.

Based on the findings of the study the following recommendations are made:

\section{* For workers}

- Remember to stand, stretch and walk for at least a minute or two every half hour.

- Workers should participate in regular physical activity and adjustment of nutrition to reduce overweight and obesity

\section{References}

1. Driscoll T, Jacklyn G, Orchard J, Passmore E, Vos T, Freedman G, et al. The global burden of occupationally related low back pain:estimates from the global burden of disease 2010 study. Annals of the Rheumatic Diseases. 2014 Mar 24;73(6):975-81.

2. Hoy D, Bain C, Williams G, March L, Brooks P, Blyth $F$, et al. A systematic review of the global prevalence of low back pain. Arthritis and Rheumatism. 2012 Jun;64(6):2028-37.

3. Beatrice D. Priority Medicines for Europe and the World "A Public Health Approach to Innovation" Update on 2004 Background Paper, BP 6.24 Low back pain. 2013 Mar; 6.24-24.

4. Yao FSF, Malhotra V, Fontes ML. Low back pain and sciatica: In Yao \& Artusio's Anesthesiology: Problem oriented patient management, 7th edition. Lippincott Williams \& Wilkins publishers. 2011;49.

5. Quinette L. The prevalence of low back pain in Africa: a systematic review.BMC Musculoskeletal Disorders. Available from: http:// wwwbiomedcentralcom/1471-2474/81052007.

6. Omokhodion FO, Sanya AO. Risk factors for low back pain among office workers in Ibadan, Southwest
- Taking rest/having breaking time on working day

- Computer users should be aware of ergonomic techniques that can make their work easier and more comfortable

- For civil service office:

- Providing prevention programs take into account all these risk factors to reduce low back injuries in public office workers and improve their work environment.

- Awareness campaign program should be organized for office workers on the importance of proper ergonomics to reduce low back pain.

\section{* For health professionals.}

- Public health efforts should be directed at educating people on occupational activities and lifestyle habits.

\section{Acknowledgement}

Authors would like to thank Arba Minch University, College of medicine and health sciences for initiating them to conduct this study and financial support. Deep appreciations have gone to Walayta Sodo town Administration. Also, special thanks to data collectors, supervisors and all peoples who involved in the study directly or indirectly.

Nigeria. . Occupational Medicine. 2003;53(4):287-9. doi:10.1093/occmed/kqg063. [cited in:PubMed;PMID 12815127]

7. WHO. Identification and control of work-released diseases. Report of a WHO Expert Committee. World Health Organ Technical Report Series. 1985;714:171.

8. Kamper SJ, Apeldoorn AT, Chiarotto A, Smeets RJ, Ostelo RW, Guzman J, et al. Multidisciplinary biopsychosocial rehabilitation for chronic low back pain:Cochrane systematic review and meta-analysis. BMJ. 2015 Feb 18;350:h444. doi: 10.1136/bmj.h444.

9. Katz JN. Lumbar disc disorders and low-back pain: socioeconomic factors and consequences. J Bone Joint Surg Am. 2006; 88A:21-4. doi: 10.2106/ JBJS.E.01273.

10. Vos T, Flaxman AD, Naghavi M, Lozano M, Michaud C, Ezzati M, et al. Years lived with disability (YLDs) for 1160 sequelae of 289 diseases and injuries 1990-2010: A Systematic Analysis for the Global Burden of Disease Study 2010. Lancet. 2012 Dec 15;380(9859):2163-96.

11. Kuorinka I, Jonsson B, Kilbom A, Vinterberg $\mathrm{H}$, Biering-Sorensen F, Andersson G, et al. Standardized Nordic questionnaires for analysis of musculoskeletal 
symptoms. Appl Ergon. 1987 Sep;18(3):233-7. doi:10.1016/0003-6870(87)90010-x.

12. Nazeer M, Rao SM, Soni S, M Ravinder, T Ramakranthi, Bhupathi S. Low back pain in South Indian: Causative Factors and Preventive Measures. Scholars Journal of Applied Medical Sciences. 2015; 3(1D):234-43.

13. Burdorf A, Jansen JP. Predicting the long term course of low back pain and its consequences for sickness absence and associated work disability. Occup Environ Med. 2006;63(8):522-29. doi:10.1136/ oem.2005.019745

14. Chaiklienga $S$, Suggaravetsirib $P$, Jenny Stewart $J$. Incidence rate and risk factors associated with low back pain among university office workers in Thailand. Proceedings 19th Triennial Congress of the IEA, Melbourne 9-14 August 2015.

15. Omokhodion FO, Umar US, Ogunnowo BE. Prevalance of low back pain among staff in a rural hospital in Nigeria. Occup Med. 2000 Mar;50(2):10710.

16. Troup JDG. Causes, prediction and prevention of back pain at work. Scand J Work Environ Health. 1984;10(6):419-28.

17. Naude W, Mamabolo V, Becker J. Low back pain among hospital employees in Gauteng, South Africa: point prevalence and associated factors. Occup Health Southern Afr. 2009;15(3):25-30.

18. Guo HR, Chang YC, Yeh WY, Chen CW, Guo YL. Prevalence of musculoskeletal disorder among workers in Taiwan:A nationwide study. J Occup Health. 2004 Jan;46(1):26-36.

19. Wong TS, Teo N, Kyaw MO. Prevalence and Risk Factors Associated with Low Back Pain Among Health Care Providers in a District Hospital. Malaysian Orthopaedic Journal. 2010; 4(2):23-8.

20. Computer/Electronic Accommodations Program. Workplace Ergonomics Reference GuideAPublication of the Computer/Electronic Accommodations Program. 2nd Edition. Washington Department of Defense (USA). Available from :www.office-ergo.com.

21. Loghmani A, Golshiri P, Zamani A, Kheirmand $M$, Jafari N. Musculoskeletal symptoms and job satisfaction among office-workers: A Cross-sectional study from Iran. Acta Medica Academica. 2013; 42(1):46-54.

22. Work, Stress and Health: the Whitehall II study. International centre for health and society. Public and Commercial Services Union.2004. London, UK 2004. Available from : http://www.workstress.net/sites/ default/files/whitehall_11_study.pdf.

23. Mahatnirunkul S, Pumpisanchai W, Tapanya P. The construction of Suan Prung stress test for Thai population. Bulletin of Suan Prung. 1997;13:1-11
24. Brayfield AH, Rothe HF. An index of job satisfaction. Journal of Applied Psychology. 1951;35(5):307-11.

25. Fritz JM, Irrgang JJ. A comparison of a Modified Oswestry Low Back Pain Disability Questionnaire and the Quebec Back Pain Disability Scale. Physical Therapy. 2001;81(2):776-88.

26. Spyropoulos P, Papathanasiou G, Georgoudis G, Chronopoulos E, Koutis H, Koumoutsou F. Prevalence of low back pain in Greek Public Office Workers. Pain Physician. 2007;10(5):651-60.

27. Schneider S, Schmitt H, Schiltenwolf M. Workplace stress, lifestyle and social factors as correlates of back pain: a representative study of the German working population. Int. Arch Occup. Environ Health. 2005;78(4):253-69.

28. Zanuto EAC, Codogno JS, Christófaro DGD, Vanderlei LCM, Cardoso JR, Fernandes RA. Prevalence of low back pain and associated factors in adults from a middle-size Brazilian city. Ciênc. saúde coletiva. 2015 May;20(5):1575-82.

29. Bawab W, Ismail K, Awada S, Rachidi S, Hajje A, Salameh P. Prevalence and Risk Factors of Low Back Pain among Office Workers in Lebanon. Int J Occup Hyg. 2015;7(1):45-52.

30. Khudhir KM, Mahmood KA, Saleh KK, Hossain M. A cross sectional study to determine the prevalence and risk factors of low back pain among public technical institute staff in Kurdistan Region, Iraq [version 1; peer review: 2 approved with reservations]. F1000Research. 2017 Feb 23;6:182 (https://doi.org/10.12688/f1000research.10806.1)

31. Kanyenyeri L, Asiimwe B, Mochama M, Nyiligira John, Habtu M. Prevalence of Back Pain and Associated Factors among Bank Staff in Selected Banks in Kigali, Rwanda: A Cross Sectional Study. Health Science Journal. 2017 June;11(3):505. Available from : https:// www.researchgate.net/publication/319342469 Prevalence_of_Back_Pain__and_Associated_ Factors_among_Bank_Staff_in_Selected_Banks_in_ Kigali_Rwanda_A_Cross_Sectional_Study.

32. Freitas KPN, Barros SS, Angelo RCD, Uchoa EPB. Occupational low back pain and the sitting position: effects of labor kinesiotherapy. Revista dor. 2011;12(4):308-13. Available from : https:// www.researchgate.net/publication/282852624_ Occupational_low_back_pain_and_the_sitting_ position_effects_of_labor_kinesiotherapy/citation/ download.

33. Isa NSM, Deros BM, Sahani M, Ismail AR. Personal and Psychosocial Risk Factor for Low Back Pain among Automotive Manual Handling Workers in Selangor, Malaysia. International Journal of Public Health Research.2014;4(1):412-8. 